\title{
Online Statics: Teaching the Masses in the New Frontier
}

\section{Prof. Carisa H Ramming P.E., Oklahoma State University}

Carisa Ramming is a graduate of Oklahoma State University where she obtained degrees in Architectural Engineering and Civil Engineering Construction Management. She worked in industry for six years as licensed engineer and structural consultant for Wallace Engineering in Tulsa, OK before returning to Oklahoma State as a visiting faculty member in the School of Architecture. In 2009, Professor Ramming joined the faculty full time as an assistant professor of architectural engineering. Since that time, she has taught classes in structural analysis, timber and steel design, engineering mechanics: statics, building foundations and numerical analysis. Professor Ramming has recently been named Halliburton Outstanding Young Faculty and the Outstanding Teacher for the College of Engineering, Architecture and Technology. She has also published books for Project Lead the Way and a text on Numerical Structural Analysis. Professor Ramming enjoys spending time with the students of CEAT as the advisor of the Architectural Engineering Institute, Tau Beta Pi, Women Inspiring Successful Engineers, and CEAT Student Council.

\section{Prof. John J Phillips, Oklahoma State University}

JOHN PHILLIPS, a registered engineer and associate professor of architectural engineering, practiced as a structural engineer for nine years before returning to his alma mater to teach at Oklahoma State University. He teaches undergraduate and graduate courses including Statics, Analysis I, Foundations, Timbers, Steel, Concrete, Steel II, Concrete II, Steel III, Concrete III, and in the Comprehensive Design Studio. 
Online Statics Course - The New Frontier

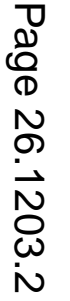




\section{Online Statics Course - The New Frontier}

\section{Introduction}

Engineering bachelors and master's degrees awarded have grown by $28 \%$ and $20 \%$, respectively, over the past decade, and the future trend is for continued growth within higher education. Sophomore and junior level engineering class enrollment increased by $9 \%$ alone between 2012 and 2013. ${ }^{7}$ With the increase in the number of students choosing engineering, entry level core engineering courses are becoming populated to the point of exceeding the resources available at some institutions. The advancement of online courses has been implemented in part to help alleviate the increase in enrollment and strain on resources, while additionally catering to the evolving student base and taking advantage of the technology at hand. The Online Learning Consortium has been conducting studies for over a decade on online courses in the U.S. ${ }^{1,2}$ A yearly report has been issued since 2002. In 2006, 2,500 responses were received and in 2014, 2,800 responses compiled the report. Reports from 2006 and 2014 yield the following: the number of students enrolled in at least one online course rose from 3.5 million students to 7.3 million. Also, in 2006, nearly $20 \%$ of students were taking at least one online course which increased to $32 \%$ by 2014 . The 2014 survey continued to indicate an increase in online enrollment even though it was the slowest rate in over a decade. The increase in online numbers has far surpassed the total from higher education. However, this new form of education does not come without its own set of issues. Online offerings within a higher education institution should strive to meet three goals, as indicated by the Sloan Consortium, and the Afred P. Sloan Foundation. Firstly, the online course must have equal or better quality compared to an oncampus course. Secondly, the course should be formatted so that it can be accessible to students anywhere, at any time, and for any number of students. Thirdly, a large number of engineering topics should be made available to online students. ${ }^{3}$ With these goals in mind, working through the logistics of offering an online course is often arduous, time consuming, and frustrating for those in charge of setting up the course, and even more so for those not familiar with the requirements of this type of course.

This paper explores the establishment of an online course in statics and the multiple issues encountered during this process. Additionally, it was important that the online course presented the material in a manner that would allow students to come away with the same understanding while being exposed to the same materials taught in the standard format for the course. Comparisons of course grades, including homework and exams, as well as results from student surveys, will be presented as an assessment of this online course.

Online learning must have skilled instructors that offer expertise and dedication to be successful. ${ }^{4}$ It is also noted that many instructors feel they are not prepared to teach online due to their training and worry that they do not possess the ability to properly facilitate an online course. This was true for the instructors at Oklahoma State University. Originally contacted in the spring semester of 2013 about establishing an online course for the upcoming summer semester, the engineering statics professors were hesitant to format an online course that would be successful at teaching the first true engineering course students take at the university. Realizing what was on the horizon, the instructors enrolled in a course offered through the university to prepare faculty for online instruction. The professors completed the six week 
course, and, a year later, with enrollment numbers rising and the need for flexibility at the forefront, the professors decided it was time to embrace the task of establishing an online course. This enrollment trend for the course is outlined in Figure 1 where data from the last five years is reflected. It can be seen that the enrollment is trending upwards, and this continued growth overcame the resource capabilities of the university for presenting this course in a single setting. The facilities available allowed for enrollments of 330 in the fall semester and 216 for the spring semester. Markers are shown where separate offerings were introduced that allowed for additional increases.

\section{Five Year Enrollment Trend}

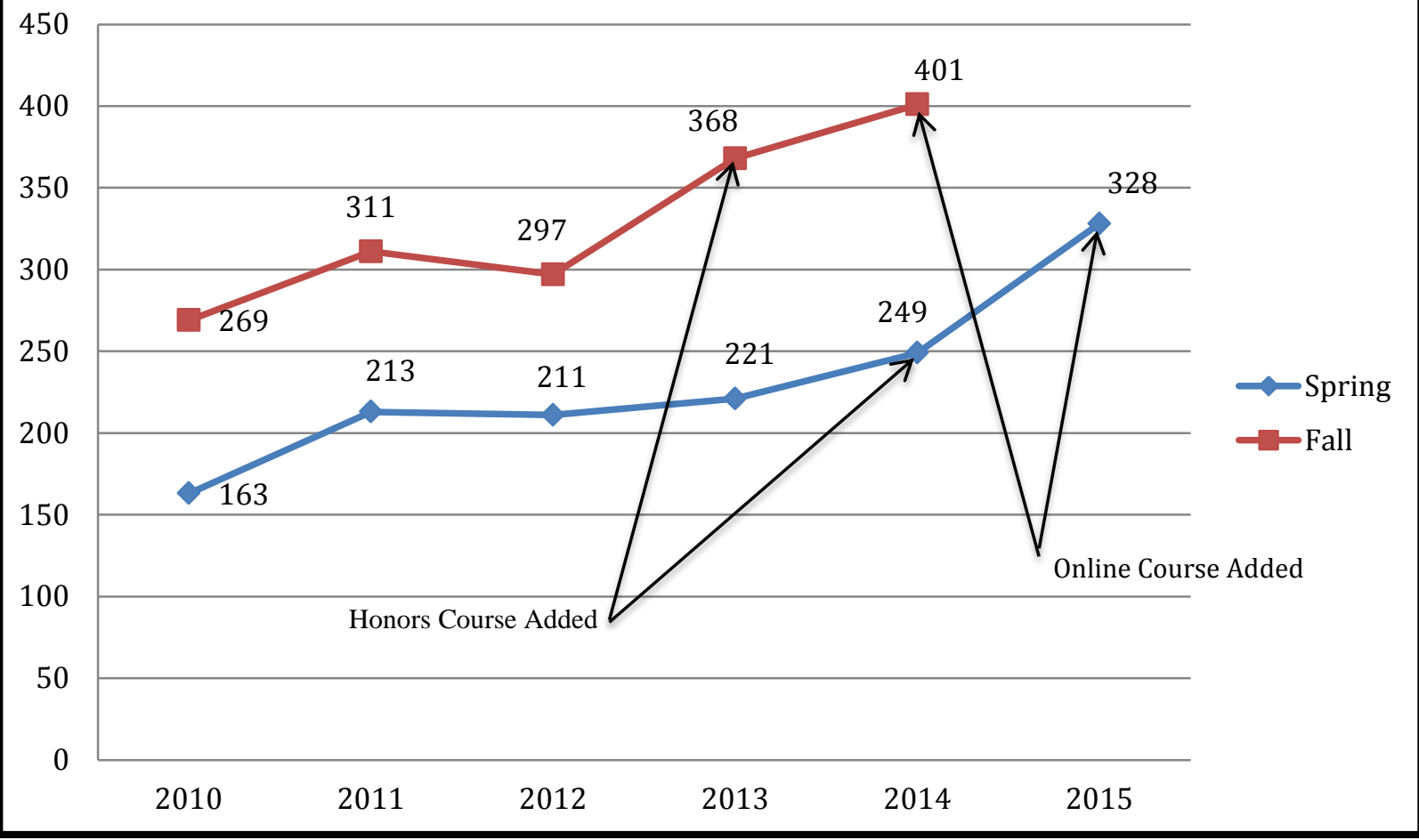

Figure 1: Statics Enrollment from 2010 - 2015

The structure of the course is typical of a core engineering course at the university. Statics is taught each semester, and consists of a three credit hour course. The course is taught in the format of three - 50 minute lecture sessions during the week for the entire class in a single lecture hall, along with a weekly 50-minute discussion lab in a smaller classroom format (24 students max). In addition to the lecture sessions held in a large auditorium, a separate section for students that are part of the Honors College also exists. This section is structured similarly, covering the same material as the large lectures and discussion lab, however, meeting at a different time and location than the general section for the course. Lecture sessions are taught by the professor assigned to the course and discussion labs are taught by teaching assistants.

The request to teach an online version of this course was made for a couple of reasons. First, the number of students enrolled in the course, not including the Honors College students, exceeded the capacity of the lecture halls, preventing any additional students from enrolling in the course. 
The college had initially dealt with the increasing number of engineering students by creating the Honors College section for this course, which removed approximately 45 students from the lecture hall and placed them in a separate lecture setting. It is important that students be allowed to take this first engineering core course in their sophomore year of the curriculum due to the requirement of the course as a prerequisite for follow-on core engineering science courses. By presenting an online version of the course, the number of students allowed to take the course would not be limited, thus giving them the opportunity to stay on track in their chosen major. Second, the college has been making a concerted effort for a number of years to advance and increase online courses through its Distance Education department, with the goals of increased enrollment, retention, and graduation within the college. Since the university is situated in what could be called a college town within an hour's drive of two metropolises, the addition of the online course would allow for students living in these cities, or even students nationally or studying abroad, the flexibility to take courses online. As other core engineering courses began moving to an online format offering, it became the opinion of much of the administration that statics should be among the online courses offered by the university.

\section{Format for the Online Course}

The U.S. Department of Education released a report in 2009 that referenced over 1,000 courses utilizing online teaching ranging from 1996 through 2008..$^{5}$ This report encompassed face to face, wholly online, and blended instruction. Within this large sampling, only 51 courses were experimental and only 28 compared the traditional face to face lecture style to a wholly online course. Of these 28 comparisons, two of these had the same instructor teaching both courses. The average study size was 84 participants. Although there were vast examples of online course instruction available, finding an exact match wasn't feasible. At Oklahoma State University, it was viewed that consistency between the two courses was important and utilizing the same instructors for both offerings was encouraged. In most of the engineering science courses that are offered at the university, the two course offerings do not parallel each other and it has proved difficult to assess the course as a whole. One reason for this is contributed to different instructors charged with the teaching of the general and online sessions. In statics, the professor in charge of the general session is also in charge of coordinating the online session, allowing the two courses to closely parallel each other. It was an important goal of the professors and the administration that the online version be structured to closely approximate the educational experience that a student enrolled in the on-campus version of the course would experience, and a comparison of the logistics of the two versions of the course is shown in Table 1. To accomplish this goal, the online course was set up with a schedule similar to the on-campus course so that lectures and assignments would be identical. This began with the class lecture sessions, which for the online course consisted of video recordings of the theory lectures and each of the examples worked in class. Each professor was responsible for recording these videos, with one of the professors being responsible for the theory lectures, and the other responsible for the examples. The intent was to have the videos appear at the same time the as the on-campus lecture and remained visible to the students throughout the entire semester. However, due to the lectures being recorded throughout the semester and delays in production of the videos, some were posted later in the day than intended. 
For homework in the course, the same homework assignments for the on-campus course were assigned to the online course. A homework assignment consisted of one problem assigned from the textbook publisher's website, and two other problems posted on the course website which were required to be worked by hand. These handwritten problems were saved as a PDF and uploaded to the course website. This came with minor issues as well. Some students found it difficult to convert images to a PDF while others struggled with technology fails (broken scanners, cameras, etc.).

Exams for large format classes are given in what is referred to as a 'Common Exam'. Common Exams are scheduled a year in advance of them happening, and occur in the evening. A few benefits exist. One advantage is that campus classrooms are more readily available for additional testing space. Another positive is that students are allowed a full 60 minutes for testing rather than the standard 50 minute allotment during lecture. It is also believed that students are not coming from or heading to a class before or after the evening exam so the probability of interference is decreased. The evening timeslot also minimizes the chances of oversleeping or transportation issues that arise with an early morning class time. Students enrolled in the online course were scheduled to take the common exams at the same time oncampus as the other sections of the course. This scheduling was done so that the same exam could be administered to all sections of the course. The option of taking the exam at an off campus location was in place. However, in this first course offering, no separate accommodations were requested.

Discussion labs are where the online course and on-campus course differ in that the online course did not have a discussion lab. The discussion lab is a time when students in smaller groups of 24 students review additional example problems, take check-point quizzes, and participate in hands-on laboratory experiments with the teaching assistants. The decision not to have a discussion lab for the online course was one that was made with much reservation. The driving factor was the dilemma of how to schedule a time when all 39 students would be able to

\begin{tabular}{|l|l|l|}
\hline Course Format & On-campus Statics & Online Statics \\
\hline Textbook & $\begin{array}{l}\text { Hibbeler, R.C., "Engineering } \\
\text { Mechanics Statics", plus use of } \\
\text { the publisher's website } \\
\text { "Mastering Engineering" }\end{array}$ & Same textbook and website \\
\hline Theory sessions & $\begin{array}{l}3 \text { times weekly for 50 minutes } \\
\text { each, covering theory/examples }\end{array}$ & $\begin{array}{l}\text { Videos posted on website } \\
\text { covering same theory/examples }\end{array}$ \\
\hline Discussion Lab sessions & $\begin{array}{l}\text { Once weekly for 50 minutes, } \\
\text { max. class size of 24 students }\end{array}$ & No Discussion Lab \\
\hline Teaching Assistant(s) & One TA per 24 students & One TA for every 25 students* \\
\hline Office Hours & 28 hours/weekly & $\begin{array}{l}\text { The on-campus hours plus } 8 \\
\text { hours/weekly of Google } \\
\text { Hangout }\end{array}$ \\
\hline Homework & Due each MWF in lecture & Same assignments / due dates \\
\hline Exams & 4 times during semester & Same exams at same time \\
\hline
\end{tabular}

*with an enrollment of 39 students in Fall 2014, only one TA was utilized

Table 1: Comparison of format for on-campus and online versions of Engineering Statics 
attend when the online course was formed only weeks before the beginning of the semester. And, how was this discussion to be offered online? The final grades were also varied in that the main course had percentages given to both homework (10\%) and discussion lab (5\%). The online course was given this entire allotment to homework (15\%). Sample lab assignments from the general and honors section of the course are provided in Appendix C.

Office hours for the course were an issue with which the professors struggled. For the oncampus course, 12 teaching assistants were able to conduct a total of 28 hours weekly, with the times set up to benefit students that had differing schedules due to other classes, labs, and work. For the online course, online office hours were established for both professors and for the teaching assistant, for a total of 8 hours per week. These were offered daily Monday through Friday and on Sunday evening. For the online office hours, Google Hangout was chosen and provided the students the opportunity to log on and interact through video and audio during the office hours. However, very few of the students actually used the system. In fact, one of the professors had no contacts during online office hours for the entire semester. The student survey given at the end of the semester revealed that for those students who utilized office hours, the vast majority of them attended the on-campus office hours. This can easily be attributed to the fact that most of the students in the online course were on campus at the university during the semester, and some of them may not be familiar or comfortable with online communication of this type.

The semester began with 39 students enrolled, and at the end of the drop period, there remained 31 in the course. Of those 31 , one of the students gave up at some point in the semester, when they stopped participating and ceased to turn in homework or attend exams.

\section{Course Survey}

In evaluating the course from the student's standpoint, a survey was presented to the class at the end of the semester. Questions pertained to course structure and resources available to the class, along with asking for suggested improvements. Students were encouraged to participate in the survey by being offered bonus points for submitting answers to the questions. Of the 31 students enrolled in the course at the time of the survey, 24 completed the survey, one student partially completed the survey, and 6 students did not participate. The survey consisted of 11 multiple choice questions, and one short answer question.

The questions were directed at the format and resources of the online course, and how potential changes could improve the educational experience of the student. Students were also asked to indicate how often they utilized the resources available, including online videos for theory and example problems, online office hours, on-campus office hours, and whether the existence of a weekly on-campus discussion session would be attended. The results of this survey are shown in Appendix B.

For $36 \%$ of the students responding to the survey, this was the first online course they had taken, compared to $28 \%$ of respondents who were taking at least their third online course. A large percentage, $64 \%$, responded that they enrolled in the online course because they could not get enrolled in the on-campus sections. A majority of respondents indicated that they watched 
theory and example videos most of the time, and a majority also said they would attend an oncampus discussion section weekly.

\section{Assessment of the Course}

In assessing the success of the students in the online course, a comparison of course grades, including homework and exams versus the general sections for the course was implemented to determine how well they performed. These grades are shown in Table 2, Table 3, and Table 4.

\begin{tabular}{|l|c|c|}
\hline \multicolumn{2}{|c|}{ Homework Average (*) } \\
\cline { 1 - 2 } General Section (310) & $78.1 \%$ & \multirow{7}{*}{$\mathbf{7 9 . 4 \%}$} \\
\hline Honors Section (33) & $92.1 \%$ & $\mathbf{7 1 . 5 \%}$ \\
\hline On-line Section (31) & $71.5 \%$ & \\
\hline
\end{tabular}

*End of semester enrollment

Table 2: Comparison of Homework Averages

\begin{tabular}{|l|c|c|}
\hline \multicolumn{2}{|c|}{ Hourly Exam Average (*) } \\
\cline { 1 - 2 } General Section (310) & $74.3 \%$ & \multirow{2}{*}{$\mathbf{7 5 . 1 \%}$} \\
\hline Honors Section (33) & $83.4 \%$ & $\mathbf{6 3 . 3 \%}$ \\
\hline On-line Section (31) & $63.3 \%$ & \\
\hline
\end{tabular}

*End of semester enrollment

Table 3: Comparison of Hourly Exam Averages

\begin{tabular}{|l|c|c|c|c|}
\hline \multicolumn{3}{|c|}{ Final Exam Average (*) } & $\begin{array}{c}\text { Standard } \\
\text { Deviation }\end{array}$ & $\begin{array}{c}\text { Standard } \\
\text { Error }\end{array}$ \\
\hline $\begin{array}{l}\text { General } \\
\text { Section (310) }\end{array}$ & $77.9 \%$ & $\mathbf{7 8 . 9 \%}$ & $\mathbf{2 4 . 3 3}$ & $\mathbf{1 . 3 2}$ \\
\hline $\begin{array}{l}\text { Honors } \\
\text { Section (33) }\end{array}$ & $88.5 \%$ & & & \\
\hline $\begin{array}{l}\text { On-line } \\
\text { Section (31) }\end{array}$ & $65.2 \%$ & $\mathbf{6 5 . 2 \%}$ & $\mathbf{2 9 . 1}$ & $\mathbf{5 . 3 1}$ \\
\hline
\end{tabular}

*End of semester enrollment

Table 4: Comparison of Final Exam Averages

Of the three comparisons, the homework average was the closest spread with only a $7.9 \%$ difference. Although the grading of the homework should be similar in nature between teaching assistants, there is some room for error. The online course homework assignments were graded by the same TA weekly while the grading of the general and honors sections rotated between TAs with each TA grading a complete assignment so that the grades were consistent. The homework average also holds the most room for error in that students may work together or with a teaching assistant or may have access to a solution. The only comparison that can eliminate these unknowns is one of the exam scores. The hourly exam averages differed by $11.8 \%$ while the final exam averages came in $13.7 \%$ apart. The final exam is comprehensive in nature and gives a clearer picture of overall learning in the course. 


\section{Lessons Learned /Future for this course}

It has been said that a professor establishing a new course can spend all the time they have preparing the course, and still not be finished. Well, for this course, a lot of the work had already been completed prior to the decision to offer the course online, and yet it still took an enormous amount of time, and after the first semester, there is still much to do. Much of the lessons learned have centered on the logistics of establishing the course, and are based in the delivery format of the course. For example, the recording of the videos for theory and example presentation took countless hours of time to record, re-record, and often, re-record again. Problems were encountered in the recording process, where at times we thought we were recording the videos only to later find out we were not, or that the sound mic had been turned off. Additionally, the conversion software experienced some problems in which the video would freeze on an image, such as a hand working an example problem, and would remain while the professor talked the rest of the way through the problem. Each of these conditions had to be corrected, and after about the first third of the course, these issues were corrected and the rest of the videoing went relatively smoothly. With the completion of the basic set of lecture and example videos, the professors will be able to enhance and add to the offerings to students in the coming semesters. For the spring 2015 semester, videos will be set to release automatically at the same time as the on-campus lecture, allowing the professors to utilize their time better in helping students in the class. Additionally, the teaching assistants will be utilized more productively in teaching the online course's discussion lab to be implemented starting in the spring 2015 semester, along with their requirement to offer on-campus office hours, allowing them to meet face to face with students enrolled in the course.

Once a semester has been completed and assessment has been performed, a professor should always evaluate a course for potential changes that could be make for the betterment of the course. For this course, with the variations in grades, and in particular, with the online grades being statistically lower in overall grades in the main three categories indicated in this paper, the professors believe changes to the course structure are warranted to enhance the learning opportunities of the students. Additional video examples and enhanced theory lectures will be provided online, as well as encouraging the use of online office hours. Currently, both online and on-campus students enrolled in the class can attend on-campus office hours, however, we do anticipate that in the future more of the students enrolled online will not live locally, making the online office hours more important.

The largest format change to the course will begin in the spring semester of 2015, with the addition of a required discussion lab, thus matching the content of the general course in statics taught on-campus. This discussion lab will be set up on-campus and those interested can attend the weekly 50 - minute lab session. For those unable to attend due to being located off campus, or for conflicting class times, students can still benefit from the discussion labs as these will be recorded and posted to the website in a similar fashion as the lecture videos. If a student is unable to attend the on-campus discussion lab, they will be required to watch the video of the lab, and to take a concept quiz. Additionally, the use of hands-on labs several times during the semester have been implemented in the on-campus course during discussion labs, and the professors have seen an increase in the comprehension of students when involved with these 
labs. ${ }^{6}$ It is the hope that by implementing these hands-on labs in a format conducive to the online course, that students will also understand the topics better.

\section{Conclusion}

With the increased importance of online courses in undergraduate curriculum, it becomes necessary to understand the effectiveness of the course as a learning environment for the students enrolled. This is especially true for courses that have physical meeting sections, and ones that are part of the core engineering science courses, which present content that is built upon in subsequent courses. One question that arose from the implementation of an online statics course at Oklahoma State University is whether such a course was ideal for an entry level engineering core course. After a single semester of offering the course, that question still lingers, as one begins to question if the on-campus version is the model or if it should become a blend of the two. Overall, though the assessment of the online course is well below that of the on-campus course, the professors involved do see the relevance of teaching statics online, and of the need for providing this format of learning to students. Revisions to the structure of the course will be made to better parallel the on-campus course format, and course assessment will continue and be expanded to potentially include grade point averages in follow-on engineering core courses (such as dynamics, and strengths of materials), as well as retention within the engineering program at the university. Currently, there is not as large of an enrollment difference between the two options and the two offerings were opened for enrollment simultaneously. This eliminates the idea that the online section was a second choice enrollment option or full of students who were re-taking the course. Research into the statistical data from the online course will continue, and data from multiple semesters in which this online course is taught will be compared to the oncampus course. This data will be used to assess the success of the students in the online course in comparison to the on-campus course. The analysis of this statistical data will allow the course instructor to evaluate the effectiveness of online statics for students. The goal of course assessments and revisions is to arrive at an online version of the course that will allow students to learn with the same success as those taking the course on-campus, giving Oklahoma State University an additional method in which to teach engineering students.

\section{References}

1. Allen, I. E., and Seaman, J. (2015). “Grade Level: Tracking Online Education in the United States, 2014”. http://www.onlinelearningsurvey.com/read/survey-reports-2014/

2. Allen, I. Elaine, and Jeff Seaman. Online Nation: Five years of growth in online learning. Sloan Consortium. PO Box 1238, Newburyport, MA 01950, 2007.

3. Bourne, J., Harris, D. and Mayadas, F. (2005), Online Engineering Education: Learning Anywhere, Anytime. Journal of Engineering Education, 94: 131-146. doi: 10.1002/j.2168-9830.2005.tb00834.

4. Chapco, Nancy, and Margaret Hunter. "Facilitating Faculty Success in the Online Learning Environment." Retrieved from https://aace-conf-media.s3.amazonaws.com/conf/site/submission/uploads/site2015/ Facilitating_Faculty_Success_in_the_Online_Learning_Environment_2015_01_29__upload_t1422548466.docx 
5. Figlio, David, Mark Rush, and Lu Yin. "Is It Live or Is It Internet? Experimental Estimates of the Effects of Online Instruction on Student Learning.” Journal of Labor Economics, 31(4), 763-784.

6. Ramming, C. H., and Phillips, J. J.(2014). "Improving Retention of Student Understanding by Use of Hands-on Experiments in Statics " Proceedings of the 2014 American Society of Engineering Educators National Conference, 2014.

7. Yoder, Brian L., "Engineering by the numbers." American Society for Engineering Education, Washington, DC. http://www.asee.org/papers-and-publications/publications/14_11-47.pdf (2014). 


\section{Appendix A: Exam problem percentages}

Exam 1:

Problem One: Placing a force in Cartesian form (10 pts)

Problem Two: 3-D moment about a point (10 pts)

Problem Three: Couple moment system (10 pts)

Problem Four: Centroid by integration (20 pts)

Problem Five: Equivalent resultant force and its distance measured from a point (25 pts)

Problem Six: Equilibrium

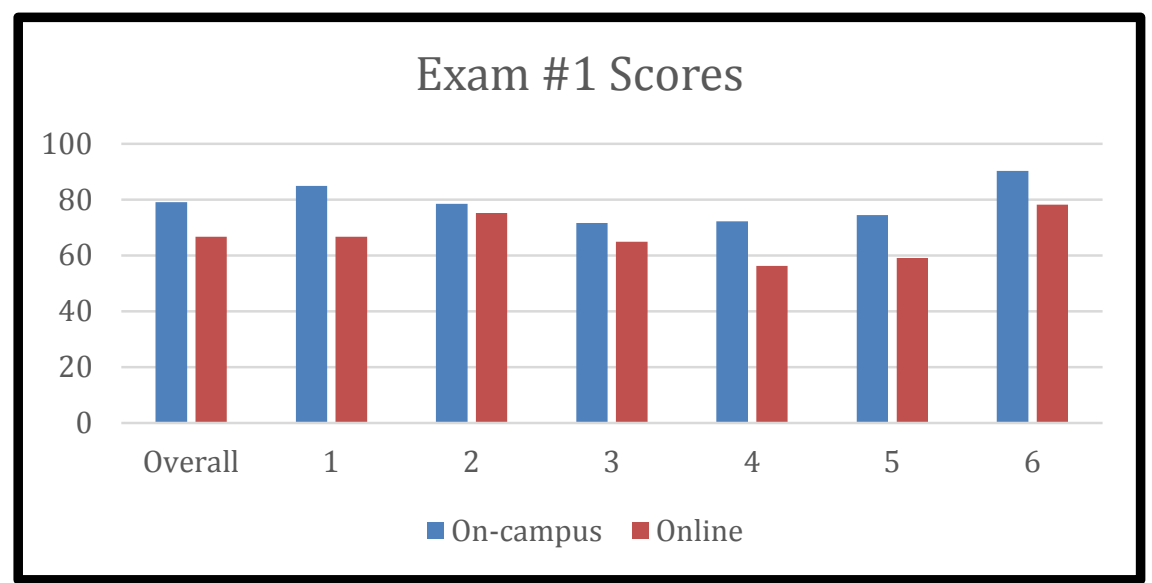

Figure 3: Exam \#1 Scores - Fall 2014

Exam 2:

Problem One: Centroid by composite bodies ( $25 \mathrm{pts})$

Problem Two: Solving 3-D support reactions (15 pts)

Problem Three: 3-D support reaction FBD (10 pts)

Problem Four: Identifying zero force members (5 pts)

Problem Five: Truss analysis (20 pts)

Problem Six: 2-D support reactions (15 pts)

Problem Seven: 2-D support reaction FBD (10 pts)

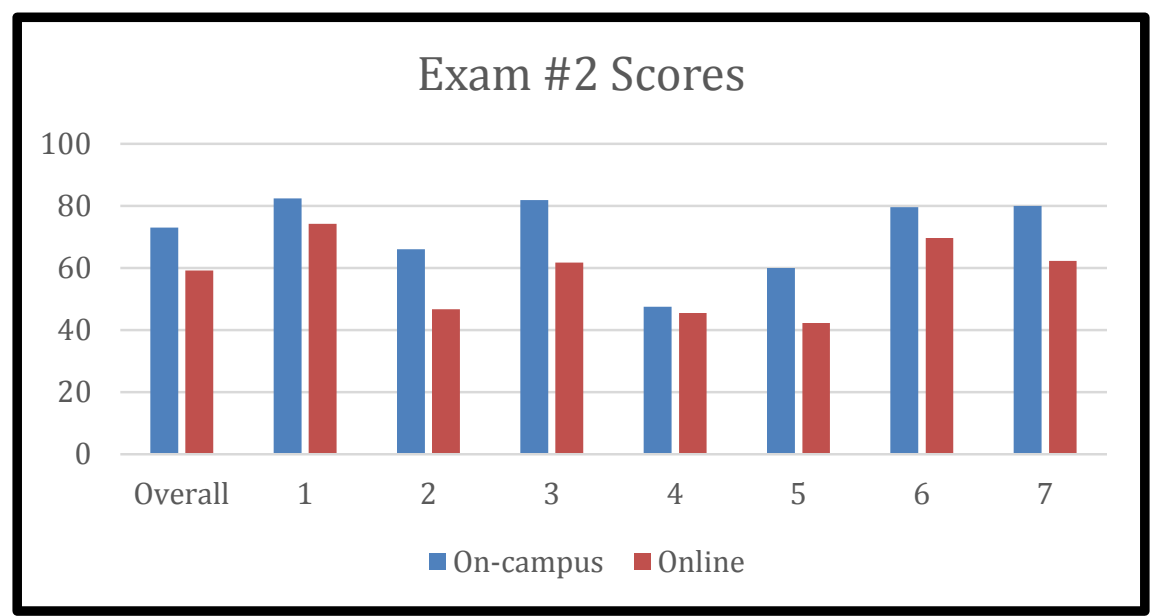

Figure 4: Exam \#2 Scores - Fall 2014 
Exam 3:

Problem One: Frame Analysis (25 pts)

Problem Two: Internal normal, shear, and bending moment at a point (15 pts)

Problem Three: Shear and moment equations (15 pts)

Problem Four: Friction (15 pts)

Problem Five: Moment of inertia by integration (15 pts)

Problem Six: Shear and bending moment diagrams (15 pts)

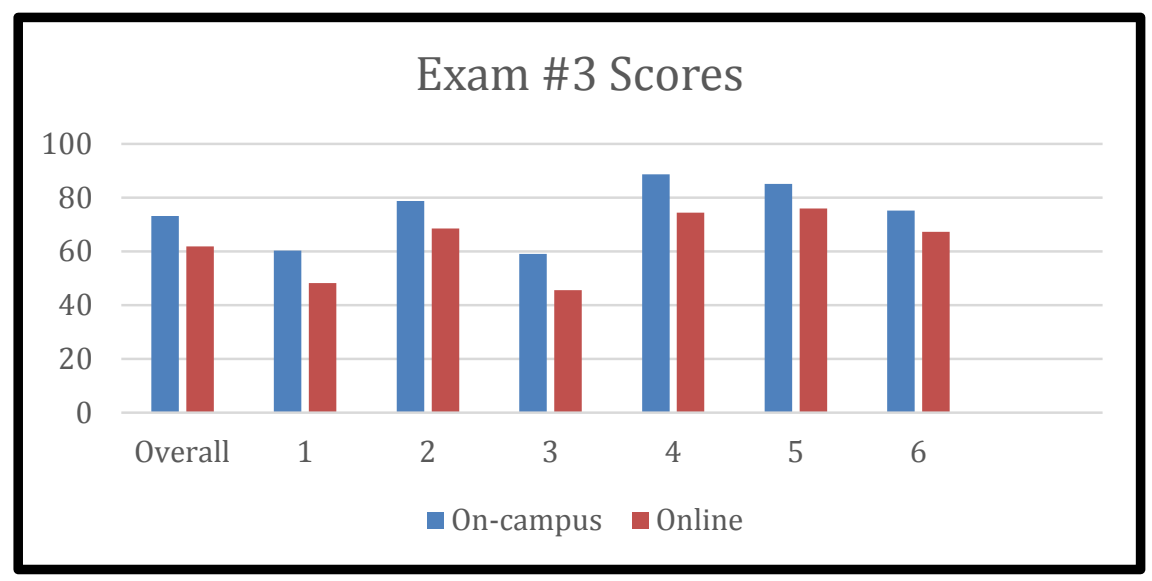

Figure 5: Exam \#3 Scores - Fall 2014

Final Exam:

Problem One: Equilibrium (10 pts)

Problem Two: Moment about a line (15 pts)

Problem Three: Moment of inertia by composite bodies (25 pts)

Problem Four: Frame analysis (25 pts)

Problem Five: Truss Analysis (25 pts)

Problem Six: Shear and bending moment equations (25 pts)

Problem Seven: Shear and bending moment diagrams (25 pts)

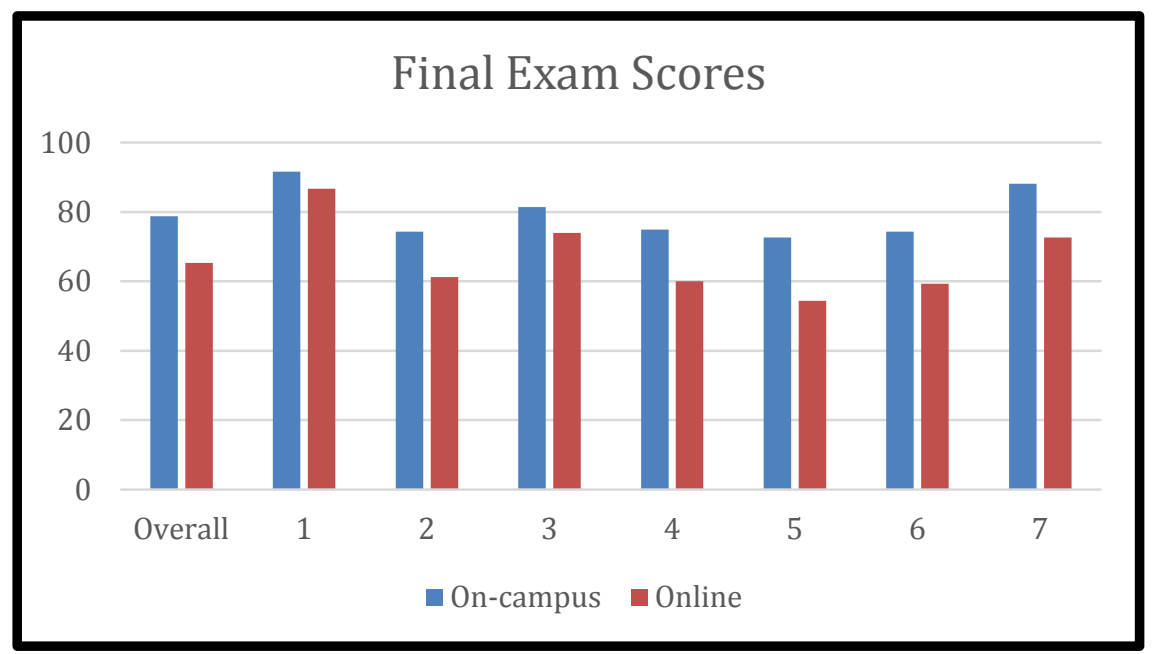

Figure 6: Final Exam Scores - Fall 2014 


\section{Appendix B: Results of Student Survey}

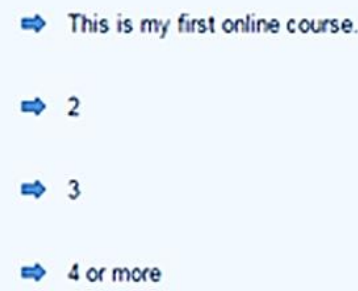

Did you enroll in this online course because you were unable to enroll in the general section for the course?

$\Rightarrow$ Yes

$\Rightarrow \mathrm{No}$

How often did you want the Lecture videos posted to the course website?

$\Rightarrow$ Regularly - Did not miss the lecture videos.

$\Rightarrow$ Mostly watched the locture videos, however, missed a few.

$\Rightarrow$ Seldom watched the lecture videos

$\Rightarrow$ Did not watch the lecture videos.

How often did you watch the Example videos posted to the course website?

$\Rightarrow$ Rogularly - Did not miss the example videcs.

$\Rightarrow$ Mostly watched the example videos, however, missed a few.

$\Rightarrow$ Seldom watched the example videos.

$\Rightarrow$ Did not watch the example videos.

How helpful do you think a discussion lab once a week would be in helping students to better understand this course?

$\Rightarrow$ Extremely helptul.

$\Rightarrow$ Somentat helpiul.

$\Rightarrow$ Unhelpful.

How often would you attend physical discussion labs held once a meek on campus?

$\Rightarrow$ Would attend discussion labs weekly.

$\Rightarrow$ Would attend discussion labs often.

$\Rightarrow$ Would attend discussion labs night before exams. 
How often did you utilize online office hours?

$\Rightarrow$ Regularly - At least once a week.

$0 \quad(0 \%)$

$\Rightarrow$ Occasionally - At least once every two weeks.

$\Rightarrow$ Seldom - At least once before each exam

$4(16 \%)$

$\Rightarrow$ Did not utilize online office hours.

How often did you utilize the physical office hours offered on campus?

$\Rightarrow$ Regularly - At least once a week.

$\Rightarrow$ Occasionally - At least once every two weeks.

$\Rightarrow$ Seldom - At least once before each exam

$\Rightarrow$ Did not utilize physical office hours on campus.

Would you participate in occasional hands-on learning labs during the semester?

$\Rightarrow$ Yes

$14(56 \%)$

$\Rightarrow$ No

Did you experience any problems submitting online homework?

$\Rightarrow$ Yes

$\Rightarrow$ No

Did you experience problems when taking the scheduled exams?

$\Rightarrow$ Yes 
For credit, please list at least one change in the format of this online class that you feel could improve the educational experience and learning potential for this course?

Collapse Responses

$\nabla$ It would be very nice if the homework for the week would all be assigned at the beginning of the week instead of every other day

Posting the exam reviews online would be helpful. And also the answers as well.

The possible addition of a physical discussion section might help since I find that talking to someone and being able to ask them questions in person, helps me to understand material better.

It was one of the best classes I have ever taken!! Test taking procedures were very good. Only change was to provide even more examples than were given if that is possible.

I really wish that D2L would list things from new to old rather than old to new. that a way when we click the content tap the most recent info (video, example, class updates) would be on the top rather than pages down the site.

also, it would be nice to have either all scanned in homework or all mastering engineering homework but not both. i personally like doing the hand written assignments because with the mastering engineering i found myself trying to do it all in my head or on my calculator, so i dont learn it as well.

I work long 4 day a week shift so the only problem I had with online course is that if im to attend physical lab once a week and visit TA's/Prof. then I might as well have taken physical class. Its not that the class is hard its just soo much to take in and I know I have missed a few assignments not because I forgot but because it was either work on statics or another 2 or 3 classes

homework or lab that's loading me down. I don't know, I cant blame the professors they are the sweetest people. Its just too much that's all i can say

I will say this though, the videos explain problem's better than any book but if you can include problems as similar to what we are doing in the homework that will be great. I think I came across 2 or 3 that did not match (in my mind) too where i could SEE the homework, ya know.

Online testing would be great but if the scheduled exams will stay physical (be on campus) then have them be earlier in the day, that would definitely help out i know every test my mind was not there AT ALL i was tired from work and class and on top of that, stressing the test and then having to hit the bus at 7:30 and get home at $9 \mathrm{pm}$ was terrible. I know that sapped $40 \%$ of my motivation... easily.

So in conclusion, mastering engineering sucks, book is OK your videos are WAAAY better, professors good people, TA's....eh. Give lighter load if possible. I have already talk to some students scheduled to take this class online and they are a taking 4-5 other class along with statics. Sorry to say they wont survive. Well i hope this helps even though i am not good at statics AT ALL, i have no regrets, prof. Ramming used understanding as best she could and no matter my grade happy.

Oh yea one more thing have online quizzes.

Thanks

Better lecture images, was not very convenient having to watch an entire lecture again to match with the image slides

Make the homework more like the exams

$\downarrow$ Work on how we submit the online homework. Just feels like half the trouble we go through of actually doing the homework it getting the document set up and uploaded on D2L.

Derhaps divide up the lectures and examples tabs under content as D2L does not load them all at once, so the majority of my homework time is spent pressing "Load More" to get to the relevant lectures.

I think a weekly discussion class would help.

$\checkmark$ I think I feel like mentioning is the timing of everything, since multiple things are do every week I feel it is crucial to be on time when updating d2 I with the necessary vides and homework, I would want to start homework early on a Tuesday or sometimes even late and wouldn't find the homework up until later that night or by Tuesday, and then you HAVE to do it Tuesday because it's due the next day. But I would definitely like to see an added session where you physic ally attend like a lab discussion or something just to ask questions or get some aspect of the actual class. It would definitely be to most peoples benifit

$D$ I think that if we were to do online quizzes of some sort to test us throughout the units, the test would become less difficult and we, as students, could get a glimpse of what the test questions might be like from a specific section or type of question.

I thought the class was amazingly organized, a lot better than my other online course.

D I was not aware of the different discussion held on campus except for the pre exam one.

I thought the class was great ... I don't think woul be need it .... Maybe the homework which is due a bit too early ... Since I don't have class at that time ...

Sometimes the example videos would freeze up for a few minute, but you could still hear him talk. If that was changed it would be great.

The example problems were very helpful but didn't always closely resemble the homework or test problems. The tests were slightly harder than homework/ review sessions.

I did not know how to utilize the online help sessions and so wasn't able to do that, but there were more than enough help sessions throughout the week.

It would be helpful to have maybe just a few more example problems offered.

1. The addition of some kind of discussion session to help show students how to work problems besides just having example recordings.

Make the examples more relevant. They were good but sometimes the homework would be more complicated than the examples. I also often felt disconnected. I understand this is bound to happen with an online course but I felt certain feedback and general information was not relayed to us that would have been beneficial to know. For example, I was told by a student in the physical class that the class was informed not to worry about the tests grades too much because they were not as high as desired. Info such as this would be nice to know. Finally, not specifically related to the online course but I personally did not feel like I had adequate time to complete the exams. I had excellent homework grades and understood the content but I struggled with the last two exams and felt like that was largely in part to the amount of problems given to us and the small amount of time.

I think would be great have an hour lab for review each week. 


\section{Appendix C: Sample Discussion Lab Material}

Sample Concept Quiz:

Name:

CWID \#:

Section Number:

ENSC 2113 - FALL 2014 - QUIZ \#2

SHOW YOUR WORK IN THE SPACE PROVIDED AND INDICATE YOUR FINAL ANSWER IN THE LIST PROVIDED FOR EACH PROBLEM TO RECEIVE CREDIT.

1) Determine the magnitudes of $F 2$ and $F 3$ for equilibrium of the particle if the force $\mathrm{F} 1=300 \mathrm{lb}$. The $600 \mathrm{lb}$ force is in the $\mathrm{x}-\mathrm{y}$ plane and the direction cosines are given for F1.

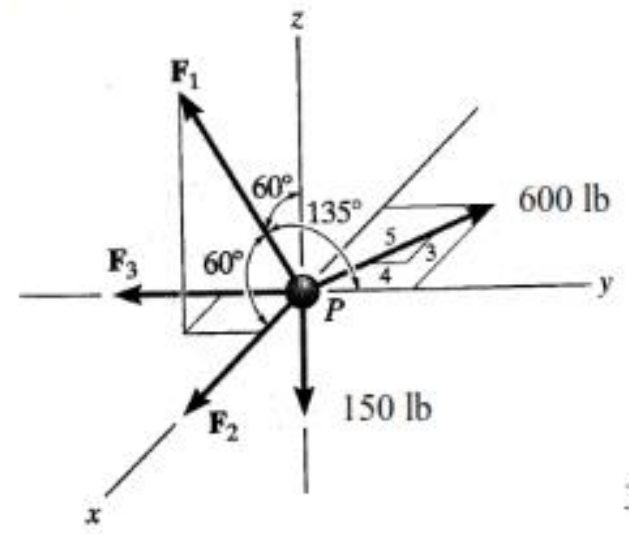
A. $\mathrm{F} 2=210 \mathrm{lb}, \mathrm{F} 3=268 \mathrm{lb}$
B. $F 2=330 \mathrm{lb}, F 3=148 \mathrm{lb}$
C. $F 2=210 \mathrm{lb}, F 3=692 \mathrm{lb}$
D. None of the above

2) Determine the moment of the $70 \mathrm{~N}$ force about point $\mathrm{A}$ if theta equals 60 degrees.

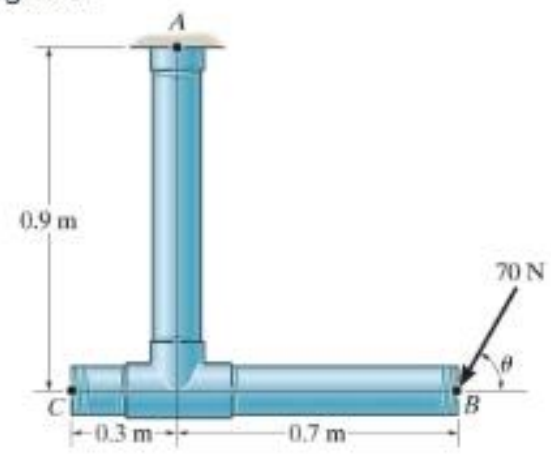
A. $74 \mathrm{~N}$-m counter-clockwise
B. $79 \mathrm{~N}$-m counter-clockwise
C. $74 \mathrm{~N}$-m clockwise
D. $79 \mathrm{~N}-\mathrm{m}$ clockwise
E. None of the above 
Hands-On Laboratories:

\section{Equilibrium of a System}

\section{ENSC 2113 Fall 2014}

\section{Purpose}

Verify the vector sum of the forces acting on an object in equilibrium is zero.

\section{Pre-lab question}

If an object is suspended by two strings at two different angles, which string will have the greater tension?

\section{Set-Up}

Clamp two rods to the table approximately 32 in $(81.3 \mathrm{~cm})$ apart using the large clamps. Attach two protractors to a cross rod and clamp this rod between the vertical rods using the small clamps.
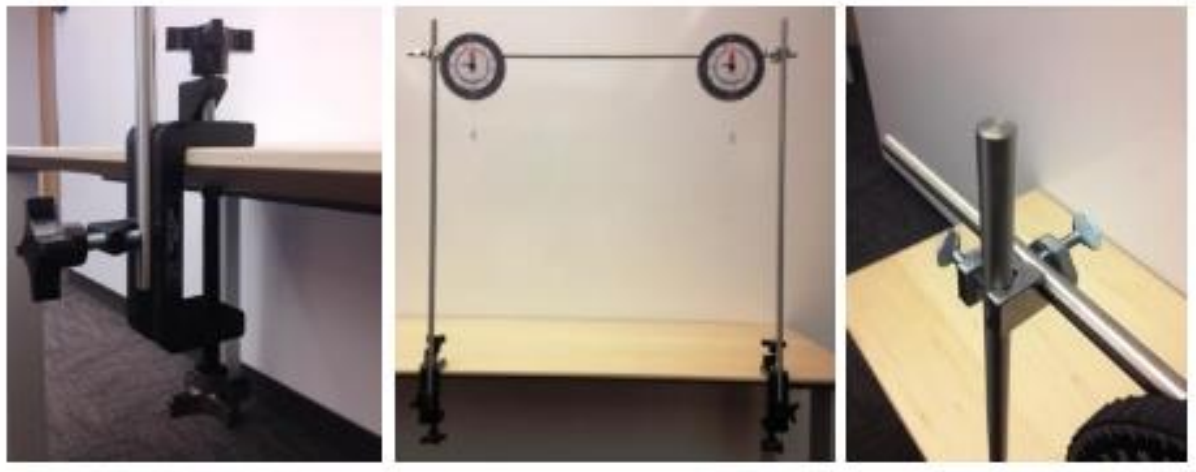
Without anything attached to the string, adjust the thumb screw in the back until the force scale reads zero. After the force scale is zeroed, hang a small mass $(10 \mathrm{~g})$ from the tension string of the protractor. Adjust the outer ring to where the string aligns with 90 degrees.
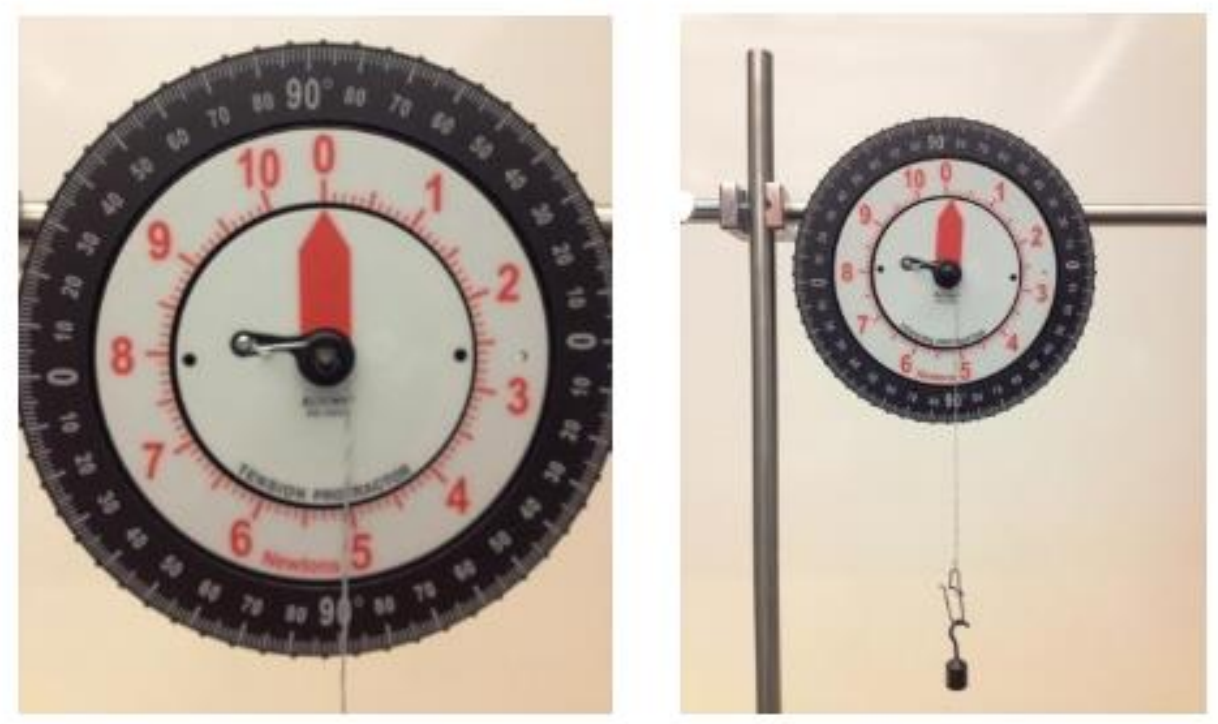

Attach the ends of the provided string to the clips on the protractor strings. Hang the $500 \mathrm{~g}$ mass from the loop located along the length of the string.

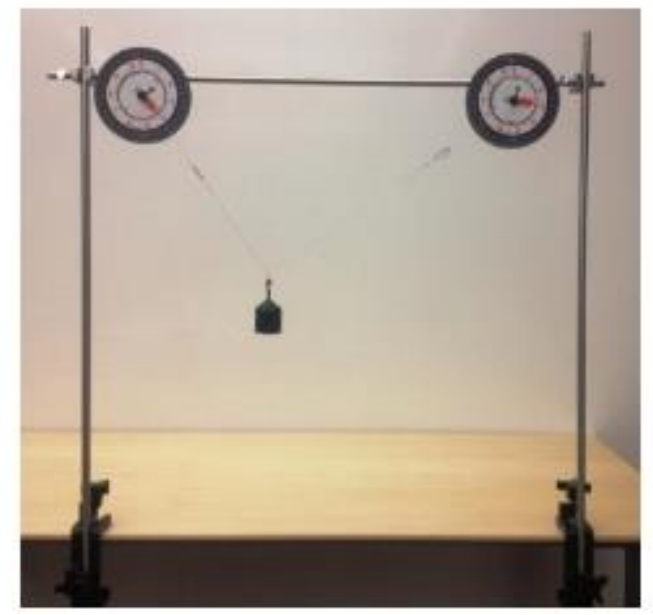




\section{Procedure}

Record the magnitude of force and the angle for each string and record them in the table below.

\begin{tabular}{|l|l|l|l|}
\hline Tension & $\begin{array}{l}\text { Magnitude of force } \\
(\mathrm{N})\end{array}$ & Angle (degrees) & Hanging Mass (kg) \\
\hline String 1 & & & \\
\hline String 2 & & & \\
\hline
\end{tabular}

Calculate the weight of the hanging mass in Newtons.

Draw the Free Body Diagram of the system. 
Calculate the $\mathrm{x}$ and $\mathrm{y}$ components of the tension of each string and record them in the table below.

\begin{tabular}{|l|l|}
\hline Weight of Hanging Mass & \\
\hline$x$-component of Tension 1 & \\
\hline$x$-component of Tension 2 & \\
\hline$y$-component of Tension 1 & \\
\hline$y$-component of Tension 2 & \\
\hline
\end{tabular}

Calculate the sum of the forces in the $\mathrm{x}$ and $\mathrm{y}$ directions. Do they equal zero? Why or why not?

If the string is rated to hold $133.5 \mathrm{~N}$ (30lbf), then what is the largest mass than can be suspended from the system? 